\title{
Malignant phyllodes tumor of the breast presenting with hypoglycemia: a case report and literature review
}

This article was published in the following Dove Press journal:

Cancer Management and Research

8 December 2014

Number of times this article has been viewed

\author{
Toni Pacioles' \\ Rahul Seth ${ }^{2,3}$ \\ Cesar Orellana ${ }^{3}$ \\ Ivy John ${ }^{4}$ \\ Veera Panuganty ${ }^{3}$ \\ Ruban Dhaliwal ${ }^{3,5}$ \\ 'Department of Hematology and \\ Oncology, Edwards Comprehensive \\ Cancer Center, Marshall University, \\ Huntington, WV, USA; ${ }^{2}$ Division \\ of Hematology and Oncology, \\ ${ }^{3}$ Department of Medicine, \\ ${ }^{4}$ Department of Pathology, ${ }^{5}$ Division \\ of Endocrinology, SUNY Upstate \\ Medical University, Syracuse, NY, USA
}

\begin{abstract}
Phyllodes tumors are rare fibroepithelial neoplasms that account for less than 1\% of all breast tumors and are typically found in middle-aged women. Phyllodes tumors that present with hypoglycemia are even rarer. No one morphologic finding is reliable in predicting the clinical behavior of this tumor. Surgery has been the primary mode of treatment to date. However, the extent of resection and the role of adjuvant radiotherapy or chemotherapy are still controversial. Here, we present a challenging case of malignant phyllodes tumor of the breast associated with hypoglycemia, and review the literature regarding clinical findings, pathologic risk factors for recurrence, and treatment recommendations.
\end{abstract}

Keywords: breast cancer, fibroepithelial neoplasm, neuroendocrine tumor, adjuvant treatment, non-islet cell tumor-induced hypoglycemia

\section{Introduction}

Phyllodes tumor (PT) was originally described by Johannes Muller in 1838. This entity, also referred to as cystosarcoma phyllodes, translates to a fleshy-appearing tumor with macroscopic cysts and a leaf-like histologic architecture. The currently accepted nomenclature according to the World Health Organization is PT. These tumors are biphasic fibroepithelial neoplasms with diverse biologic behavior, and can be benign, borderline, or malignant. PTs account for about $0.3 \%-0.5 \%$ of all female breast tumors, with an incidence of about two per million. These tumors occur almost exclusively in women, with a median age of $42-45$ years at presentation, although there are case reports in men. PT are predominantly benign, asymptomatic tumors that manifest as large masses. The median size of a PT is 4-7 cm, and it may cause fatigue, dyspnea, and bone pain in metastatic disease. Non-islet cell tumorinduced hypoglycemia (NICTH), although more commonly associated with other mesenchymal tumors, is indeed a rare paraneoplastic sequela of PT. PT associated with NICTH typically grows to greater than $10 \mathrm{~cm}$. While PT leading to NICTH generally develops over several years, rapid growth is possible. Different treatment modalities for management of PT have been proposed in the literature, but there are no standards of care. Complete excision of the tumor with continued follow-up is key to management.

Here we report a case of PT presenting with NICTH, discuss the management of NICTH and risk factors for local recurrence of PT, and review the various treatment modalities. ${ }^{1-4}$
Correspondence: Toni Pacioles Department of Hematology and Oncology, Edwards Comprehensive Cancer Center, Marshall University, $1400 \mathrm{Hal}$ Greer Boulevard, Huntington, WV 2570I, USA

$\mathrm{Tel}+\mid 304399655$ I

Fax +I 3043996667

Email toni.pacioles@chhi.org 


\section{Case report}

A 51-year-old Caucasian female with a 3-month history of a rapidly growing right breast mass presented with altered mental status. She had no other medical problems. Her social history included a 20 pack per day smoking history but no alcohol or illicit drug use. Upon presentation, fingerstick glucose was $16 \mathrm{mg} / \mathrm{dL}$. Physical examination was remarkable for a large, firm, mobile, fungating, right breast mass measuring $29.5 \times 26.0 \times 14.0 \mathrm{~cm}$, with a necrotic core and three ulcerated lesions (Figure 1A and B). Fine needle aspiration of the mass one month before this episode was nondiagnostic. Pertinent negative findings on physical examination showed no lymphadenopathy or hepatosplenomegaly.

During hospitalization, she experienced recurrent daily fasting hypoglycemia associated with tremors, fatigue, cold sweats, and confusion despite multiple dextrose injections and continuous $5 \%$ dextrose infusion. A continuous $10 \%$ dextrose infusion was ultimately required to achieve euglycemia. Initial laboratory data were as follows: potassium $2.8 \mathrm{mmol} / \mathrm{L}$, glucose $51 \mathrm{ng} / \mathrm{dL}$, and random cortisol $18.4 \mu \mathrm{g} / \mathrm{dL}$ (Table 1). Computed tomography of the chest and abdomen was negative for metastasis. A whole body bone scan also showed no evidence of metastatic bone disease. Further investigations excluded systemic illness, thyroid dysfunction, adrenal insufficiency, drugs, or hyperinsulinism as potential causes of her hypoglycemia. A serum sulfonylurea screen was negative. Insulin $(<2.0 \mu \mathrm{U} / \mathrm{mL})$, c-peptide $(<0.1 \mathrm{ng} / \mathrm{mL})$, and $\beta$-hydroxybutyrate $(0.03 \mathrm{mmol} / \mathrm{L})$ levels were low (Table 2).

The absence of $\beta$-hydroxybutyrate and low insulin levels raised suspicion for insulin-like growth factor (IGF)mediated hypoglycemia. The IGF-I level was low $(39 \mathrm{ng} / \mathrm{mL}$, reference range $53-287 \mathrm{ng} / \mathrm{mL}$ ) while the IGF-II level was normal $(658 \mathrm{ng} / \mathrm{mL}$, reference range $288-736 \mathrm{ng} / \mathrm{mL})$. IGF-I was measured by quantitative chemiluminescent immunoassay and IGF-II by radioimmunoassay. Notably, the IGF-II/ IGF-I ratio was elevated at 17 (reference range $<10$ ). The patient also had an adequate response to $1 \mathrm{mg}$ intravenous

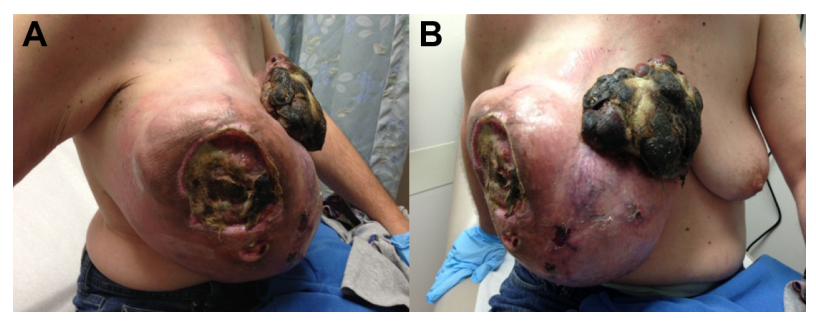

Figure I (A and B) Right chest wall mass measuring $29.5 \times 26.0 \times 14.0 \mathrm{~cm}$ that ulcerated the overlying skin and formed a fungating necrotic skin lesion.
Table I Initial laboratory findings

\begin{tabular}{lll}
\hline Component & Reference range & Result \\
\hline Calcium & $8.4-10.2 \mathrm{mg} / \mathrm{dL}$ & $9.4 \mathrm{mg} / \mathrm{dL}$ \\
Creatinine & $0.4-1.1 \mathrm{mg} / \mathrm{dL}$ & $0.3 \mathrm{mg} / \mathrm{dL}(\mathrm{L})$ \\
Glucose & $65-110 \mathrm{mg} / \mathrm{dL}$ & $51 \mathrm{mg} / \mathrm{dL}(\mathrm{L})$ \\
Alkaline phosphatase & $35-104 \mathrm{U} / \mathrm{L}$ & $84 \mathrm{U} / \mathrm{L}$ \\
Potassium & $3.3-5.1 \mathrm{mmol} / \mathrm{L}$ & $2.8 \mathrm{mmol} / \mathrm{L}(\mathrm{LL})$ \\
Sodium & $133-145 \mathrm{mmol} / \mathrm{L}$ & $142 \mathrm{mmol} / \mathrm{L}$ \\
AST (SGOT) & $<32 \mathrm{U} / \mathrm{L}$ & $21 \mathrm{U} / \mathrm{L}$ \\
ALT (SGPT) & $<31 \mathrm{U} / \mathrm{L}$ & $13 \mathrm{U} / \mathrm{L}$ \\
TSH & $0.27-4.20 \mu \mathrm{U} / \mathrm{mL}$ & $0.899 \mu \mathrm{U} / \mathrm{mL}$ \\
Free thyroxine & $0.90-1.70 \mathrm{ng} / \mathrm{dL}$ & $1.12 \mathrm{ng} / \mathrm{dL}$ \\
Cortisol & $2.3-11.9 \mu \mathrm{dL}$ & $18.4 \mathrm{ng} / \mathrm{dL}$ \\
\hline
\end{tabular}

Abbreviations: ALT, alanine aminotransferase; SGPT, serum glutamic-pyruvic transaminase; AST, aspartate aminotransferase; SGOT, serum glutamic oxaloacetic transaminase; TSH, thyroid-stimulating hormone; L, low; LL, very low.

glucagon stimulation, with serum glucose levels of $43 \mathrm{ng} / \mathrm{mL}$, $76 \mathrm{ng} / \mathrm{mL}$, and $91 \mathrm{ng} / \mathrm{mL}$ at baseline, and 15 and 30 minutes, respectively, following glucagon administration.

Repeat biopsy of the breast mass revealed a desmoid tumor with fibroelastic tissue. The patient underwent a wide (radical) resection of the right chest wall with muscle flap placement and a skin graft. Histopathology of the right breast mass (Figures 2 and 3) showed a malignant, high-grade PT with a tiny focus of invasive ductal carcinoma. There was no lymphovascular or perineural invasion. Margins were negative. Estrogen and progesterone receptors were positive. Human epidermal growth factor receptor 2 was negative.

A 5\% dextrose infusion was continued in the immediate postoperative period. Hypoglycemia resolved within the next few days and the patient was discharged home. The IGF-II/ IGF-I ratio also normalized (Table 3). The patient did not receive adjuvant treatment for this high-grade PT because she was lost to follow-up.

\section{Discussion}

Although PTs are predominantly benign and asymptomatic growths, in rare cases large tumors can present with hypoglycemia. This case highlights the complexities surrounding the diagnosis and management of NICTH caused by PT, a rare clinical entity.

Table 2 Additional laboratory values

\begin{tabular}{lll}
\hline Component & Reference range & Result \\
\hline Insulin & $2.6-24.9 \mu \mathrm{U} / \mathrm{mL}$ & $<2.0 \mu \mathrm{U} / \mathrm{mL}(\mathrm{L})$ \\
Glucose & $65-110 \mathrm{mg} / \mathrm{dL}$ & $32 \mathrm{mg} / \mathrm{dL}(\mathrm{LL})$ \\
$\beta$-hydroxybutyrate hydroxybutyrate & $\leq 0.28 \mathrm{mmol} / \mathrm{L}$ & $0.03 \mathrm{mmol} / \mathrm{L}$ \\
C-peptide & $0.8-3.5 \mathrm{ng} / \mathrm{mL}$ & $<0.1 \mathrm{ng} / \mathrm{mL}(\mathrm{L})$ \\
Proinsulin & $\leq 26.8 \mathrm{pmol} / \mathrm{L}$ & $<2.5 \mathrm{pmol} / \mathrm{L}$ \\
\hline
\end{tabular}

Abbreviations: ; L, low; LL, very low. 


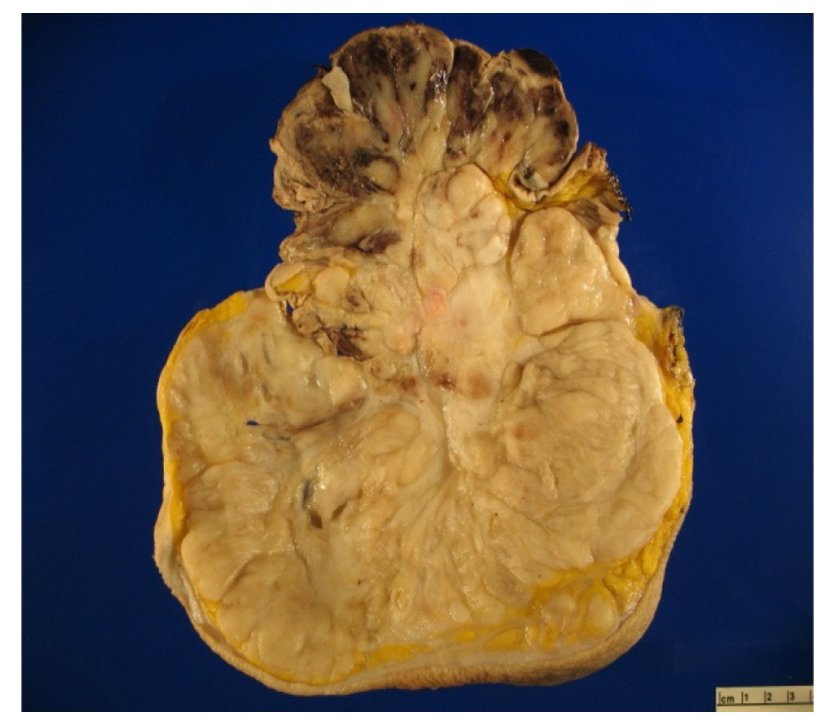

Figure 2 Sectioning revealed a nodular mass having a tan-white fleshy cut surface with both myxoid and fibrous areas, along with scattered areas of necrosis. The area corresponding to the fungating lesion had a necrotic rim with a hemorrhagic cut surface.

NICTH is a paraneoplastic process, the incidence of which is not known. Half of NICTH cases arise in the setting of mesenchymal malignancy. Solitary fibrous tumors have been implicated, as well as sarcomas, including mesothelioma, leiomyosarcoma, and fibrosarcoma. Tumors that cause NICTH are generally greater than $10 \mathrm{~cm}$ in diameter. NICTH primarily occurs in a fasting state. Multiple mechanisms underlie NICTH. This hypoglycemia is a result of inhibited hepatic glycogenolysis, and gluconeogenesis and diminished lipolysis in adipose tissue, indicating increased
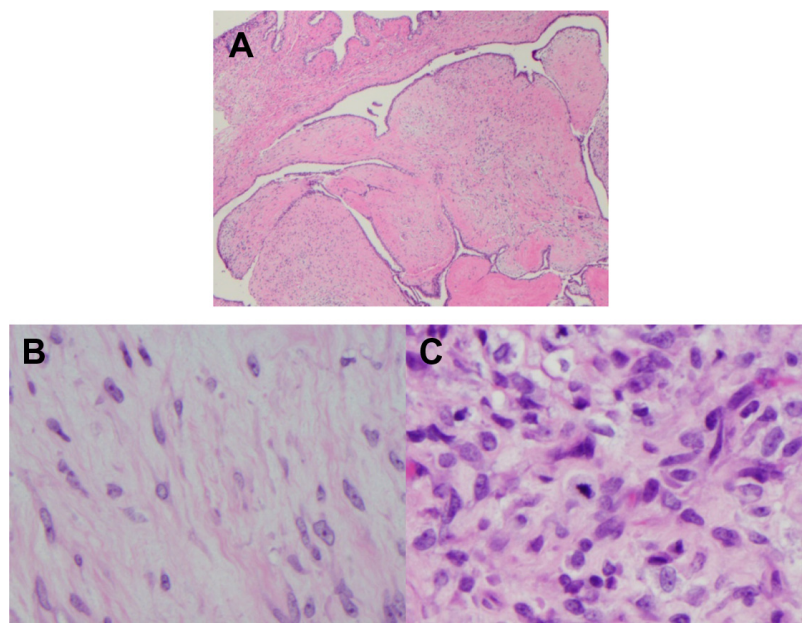

Figure 3 Microscopic examination of the resected specimen (I0x magnification) showed a malignant phyllodes tumor with extensive stromal overgrowth $(\mathbf{A})$. The stromal component varied in cellularity, with some areas (50× magnification) having a low-grade appearance (B), while others (50× magnification) had a more high-grade appearance with increased cellularity, nuclear pleomorphism, and numerous mitotic figures (C).
Table 3 Insulin-like growth factor values

\begin{tabular}{llll}
\hline Component & Reference range & Preoperative & Postoperative \\
\hline IGF-I & $53-287 \mathrm{ng} / \mathrm{mL}$ & $39 \mathrm{ng} / \mathrm{mL}$ & $128 \mathrm{ng} / \mathrm{mL}$ \\
IGF-II & $288-736 \mathrm{ng} / \mathrm{mL}$ & $658 \mathrm{ng} / \mathrm{mL}$ & $372 \mathrm{ng} / \mathrm{mL}$ \\
IGF-II/IGF-I & $<10$ & 16.87 & $2.9 \mid$ \\
\hline
\end{tabular}

Abbreviation: IGF, insulin-like growth factor.

insulin-like activity in the body. Additionally, enhanced glucose utilization due to the high metabolic needs of a large tumor may contribute to hypoglycemia. Endogenous insulin secretion is suppressed appropriately in NICTH. The $\beta$-hydroxybutyrate level is low and the glucose response to glucagon stimulation is normal. Several studies have shown that IGF is a key component in the pathogenesis of NICTH. ${ }^{5-7}$ Often, it is the result of increased production and bioavailability of pro-IGF-II, which promotes insulin-like feedback inhibition of growth hormone, although there are some reports of overproduction of IGF-I.

Mature IGF-II is synthesized as a 180 amino acid preprohormone. A C-terminal extension of 89 amino acids is known as the E-domain. During intracellular processing, a signal peptide as well as the E-domain is cleaved, resulting in mature IGF-II. Big IGF-II, a form of pro-IGF-II, results when the E-domain is not completely cleaved from pro IGF-II. In normal serum, less than $10 \%$ of circulating IGF-II is big IGF-II; however, several malignancies, including sarcoma, can secrete large amounts of big IGF-II. Big IGF-II is biologically active, and the bioavailability of IGF-II at target tissues is increased, leading to overstimulation of the insulin receptor, resulting in hypoglycemia. ${ }^{8}$

Suppression of growth hormone at the level of the pituitary by negative feedback mechanisms leads to universally depressed IGF-I levels. For this reason, an IGF-II/IGF-I ratio can be a useful diagnostic indicator of IGF-II producing NICTH. In a case series of 44 patients with NICTH, IGF-II/ IGF-I ratios were anywhere between 16.4 and 64.2, with a mean of $35.0 \pm 2$ in NICTH with big IGF-II. ${ }^{7}$

In this case, the pre-excision IGF-I was $39 \mathrm{ng} / \mathrm{mL}$, which is below the lower limit of the reference range for the laboratory $(53 \mathrm{ng} / \mathrm{mL}$ ) and the IGF-II level was $658 \mathrm{ng} / \mathrm{mL}$ (normal range $288-736 \mathrm{ng} / \mathrm{mL}$ ). Post-excision levels of both IGF-I $(128 \mathrm{ng} / \mathrm{mL})$ and IGF-II $(372 \mathrm{ng} / \mathrm{mL})$ were within the reference range. The molar pre-excision IGF-II/IGF-I ratio was 16.87 (normal $<10 \mathrm{ng} / \mathrm{mL}$ ), meeting the criteria for NICTH. The post-excision IGF-II/IGF-I ratio was 2.91.

Hypoglycemia caused by IGF-II in large tumors is severe. In this patient, hypoglycemia led to confusion and delirium. In the literature, other symptoms including 
Table 4 Summary of chemotherapeutic agents and response to treatment

\begin{tabular}{|c|c|c|}
\hline Study (location) & Regimen & Comments \\
\hline Morales-Vasquez et $\mathrm{al}^{21}$ & Doxorubicin $65 \mathrm{mg} / \mathrm{m}^{2}$ and dacarbazine & 5 -year RFS was $58 \%$ for those who received adjuvant \\
\hline (MD Anderson Cancer Center) & $960 \mathrm{mg} / \mathrm{m}^{2}$ both given over 48 hours & chemotherapy but there was no effect on survival \\
\hline Allen et $\mathrm{al}^{24}$ (Emory University) & $\begin{array}{l}\text { Doxorubicin and cisplatin every } 3 \text { weeks for } \\
\text { six courses }\end{array}$ & $\begin{array}{l}\text { Pulmonary metastases in complete remission; brain metastasis } \\
\text { developed later on }\end{array}$ \\
\hline Burton et al ${ }^{22}$ (Duke University) & $\begin{array}{l}\text { Cisplatin } 100 \mathrm{mg} / \mathrm{m}^{2} \text { and etoposide } 300 \mathrm{mg} / \mathrm{m}^{2} \\
\text { each divided over } 3 \text { days }\end{array}$ & $\begin{array}{l}\text { Greater than } 50 \% \text { reduction in all measurable disease } \\
\text { consistent with a partial remission }\end{array}$ \\
\hline Hawkins et $\mathrm{al}^{23}$ (Marsden & Ifosfamide $5 \mathrm{~g} / \mathrm{m}^{2}$ for eight cycles & Two had complete remission that lasted 26 and 61 months, \\
\hline Hospital, England) & & respectively; one with a partial response that lasted I 3 months \\
\hline
\end{tabular}

Abbreviation: RFS, relapse-free survival.

anxiety, irritability, weakness, severe sweating, and coma, have been described. Initial treatment of hypoglycemia can be oral glucose, and glucagon can be used to ameliorate acute hypoglycemia. Recurrent or severe hypoglycemia requires continuous infusion of dextrose-based fluids. Treatment of NICTH with continuous glucagon infusion has also been reported. Once the tumor is identified, its excision is the mainstay of treatment, and complete resection leads to rapid resolution of hypoglycemia, as seen in this case. While awaiting surgical resection or when total resection of the tumor is not feasible due to a large tumor burden or metastatic disease, glucocorticoids may be used to treat NICTH via reduction in IGF-II levels. In rare cases, hypoglycemia may recur with tumor recurrence.

Previous research studies have provided evidence of a role for IGF-II in hypoglycemia associated with non-islet cell tumors. Renard et al reported a patient who presented with severe neurologic deficit and hypoglycemia associated with NICTH. The hypothesis of an insulinomimetic compound released by tumor cells was supported because of the abnormal presence of a high-weight and immature form of IGF-II in the serum identified by Western immunoblot analysis. A mastectomy was performed and the hypoglycemia resolved. ${ }^{9}$ In a subsequent study of a patient who presented with hypoglycemia, behavioral changes, and a giant breast mass, Hino et al suspected that IGF-II was produced by the breast tumor and was the likely cause of the hypoglycemia. A Western blot analysis revealed that IGF-II (20 kDa) was the predominant serum IGF-II peptide (mature IGF-II is $7.5 \mathrm{kDa}$ ). After mastectomy, the hypoglycemia resolved, and endogenous insulin levels improved. ${ }^{10}$ Aguiar et al reported a similar case of PT of the breast presenting with hypoglycemia in which the patient developed an irreversible hypoglycemic coma secondary to production of IGF-II by the tumor. ${ }^{11}$ Similarly, Kataoka, et al reported the case of a patient developing hypoglycemia associated with IGF-II produced by a giant malignant PT that consumed glucose.
After removal of the tumor, the blood sugar level normalized and the IGF-II level decreased. ${ }^{12}$

\section{Pathology}

PTs are rare fibroepithelial neoplasms of the breast that can potentially be aggressive. They are classified as benign, borderline, or malignant. Benign PTs are characterized by increased stromal cellularity, mild to moderate cellular atypia, well-circumscribed tumor margins, less than four mitoses per ten high power fields, and lack of stromal overgrowth. Borderline tumors have a higher degree of stromal cellularity and atypia, four to nine mitoses per ten high power fields, and positive infiltrative borders, and lack stromal overgrowth. Malignant PTs are the most aggressive, and are characterized by marked stromal cellularity and atypia, positive infiltrative margins, more than ten mitoses per ten high power fields, and stromal overgrowth. ${ }^{13,14}$ Benign and borderline PTs rarely recur following wide excision, and have improved local control and disease-free survival compared with patients who have malignant lesions. ${ }^{15,16}$ Stromal overgrowth is associated with aggressive behavior and a high rate of distant failure. ${ }^{17}$

\section{Prognostic factors}

PTs exhibit unpredictable behavior regardless of histologic grade. In a retrospective study, risk factors for local recurrence were a positive resection margin and tumor size. ${ }^{18}$ The presence of tumor cells on the resection margin was a strong prognostic factor for local recurrence of PTs. The standard treatment is surgical excision, with a clear resection margin of more than $1 \mathrm{~cm}$ to minimize the risk of recurrence. However, based on that study, a $1 \mathrm{~cm}$ negative margin thickness did not confer any local control advantage over a thinner negative margin width. Only a positive surgical resection margin was associated with an increased rate of local recurrence. In addition, the size of the tumor was a significant prognostic indicator for local recurrence. Histologic grade was not a significant predictor of local recurrence. 
In a retrospective study of 352 cases of PT from 1954 to 2005, positive margins, fibroproliferation rate, stromal pattern, stromal cellularity, frequency of mitosis, and necrosis were associated with an increase in local recurrence rates. ${ }^{1}$ A higher local recurrence rate was associated with positive margins, fibroproliferation, and necrosis. PTs classified as malignant did not have a higher risk of local recurrence. Only five of the 352 patients developed distant metastases. These patients had uniformly aggressive pathologic features, including large tumor size, infiltrative borders, marked stromal overgrowth, marked stromal cellularity, high mitotic count, and necrosis. They proposed that six variables be taken together to identify a subgroup of PTs at high risk for distant disease, ie, a large $(>7 \mathrm{~cm})$ tumor size, infiltrative borders, marked stromal overgrowth, marked stromal cellularity, more than five mitoses per ten high power fields, and necrosis.

In another study investigating prognostic factors, tumor margin, growth of the connective tissue component, mitosis, and cellular atypia were analyzed in the records of 170 women with PT of the breast. Of the 170 treated patients, $141(82.9 \%)$ survived 5 years without evidence of disease. In this analysis, the histotype of the tumor was the only independent prognostic factor. ${ }^{2}$

\section{Surgery}

Patients with malignant PTs of the breast are routinely treated with surgery alone. A retrospective review of malignant PTs in 478 patients was conducted to determine local control rates based on tumor size and type of surgery performed. Five-year local control rates were higher for patients treated with mastectomy compared with lumpectomy. This review demonstrated that local control was related to tumor size, in that the greater the tumor size, the better the local control rate. For mastectomy patients, local control rates exceeded $85 \%$ for all patients except those with tumors $>10 \mathrm{~cm}$. For lumpectomy patients, local control rates exceeded $85 \%$ only for those with tumors $<2 \mathrm{~cm} .{ }^{19}$

Prior research demonstrates the importance of the type of surgical procedure with regard to recurrence rates. One study compared types of surgical procedures among 172 patients with malignant PTs. Wide excision or mastectomy with negative surgical margins yielded high local control rates, and local excision was associated with a relatively high percentage of positive surgical margins. ${ }^{3}$

\section{Radiotherapy}

A significant number of patients with malignant PT may develop local recurrence. The value of adjuvant radiation therapy in reducing local recurrence rates is unclear and controversial because only a small fraction of patients have received radiation therapy. Radiotherapy may have a role in the treatment of PT depending on the number of recurrences, mitotic index, bulky tumor, status of resection margins, and p53 and Ki67 expression. ${ }^{20}$ Adjuvant radiation therapy has been recommended for malignant PTs in the belief that this should be managed as a soft tissue sarcoma with resection and to reduce the risk of local recurrence. Some authors recommend radiation therapy for patients with positive surgical margins, tumor size $>5 \mathrm{~cm}$, and for patients who received lumpectomy for primary treatment. The recommended radiation dose was 50 Gy delivered over 5-5.5 weeks to the region at risk of occult residual disease followed by a local boost to the tumor bed for an additional 10-15 Gy over 1-2 weeks. ${ }^{19}$

\section{Chemotherapy}

The benefit of adjuvant chemotherapy is controversial. There have been no published randomized studies of adjuvant therapy specifically in PTs. In an observational study, 28 patients with malignant PTs of the breast received four cycles of adjuvant chemotherapy (doxorubicin $65 \mathrm{mg} / \mathrm{m}^{2}$ and dacarbazine $960 \mathrm{mg} / \mathrm{m}^{2}$ ). All patients underwent surgical resection. At a median follow-up of 15 months, there were seven recurrences and five deaths. The 5-year relapse-free survival rate was $58 \%$ for those who received adjuvant chemotherapy and $86 \%$ for those who did not. Median survival after recurrence was 6.5 months. Adjuvant chemotherapy with doxorubicin and dacarbazine did not affect patient survival (Table 4). ${ }^{21}$

In one case report, cisplatin and etoposide was found to be an effective option. Radiation therapy was effective in controlling symptomatic metastasis in all three patients treated. ${ }^{22}$ The patients received seven courses of cisplatin and etoposide, which resulted in a $>50 \%$ reduction in all measurable disease, consistent with a partial remission. However, chemotherapy was discontinued because of peripheral neuropathy.

In a case series in 1991, three patients with metastatic disease were treated with ifosfamide alone and one patient was treated with a combination of ifosfamide and doxorubicin. This study provided examples of significant improvement in progression-free survival and objective response rates with ifosfamide. Ifosfamide appeared to compare favorably with other treatments, but the effectiveness of combined therapy with doxorubicin could not be assessed due to the limited sample size. ${ }^{23}$

Based on limited data, adjuvant chemotherapy should be administered only for a minority of patients with 
large $(>5 \mathrm{~cm})$, high-risk, or recurrent malignant tumors. A thorough discussion about the risks and benefits of treatment should be undertaken with the patient. For benign or borderline PTs, chemotherapy should not be offered. Finally, guidelines for treating sarcomas rather than adenocarcinomas of the breast should be followed in patients with malignant PTs. ${ }^{13}$

\section{Hormonal therapy}

Estrogen dependency has not been linked to the growth of PTs. In one study, expression of epithelial estrogen and progesterone receptor proteins was common, occurring in $43 \%-84 \%$ of PTs. ${ }^{25}$ Despite the high percentage of estrogen/ progesterone receptor-expressing PTs, hormonal therapy was ineffective. ${ }^{26}$

\section{Conclusion}

We reported on a middle-aged female with a large right breast mass who underwent wide radical resection and required a muscle flap placement. Pathology was consistent with malignant PT. Concomitantly, the patient had symptomatic hypoglycemia secondary to her PT with an elevated IGF-II/ IGF-I ratio, thereby fulfilling the criteria for NICTH. The hypoglycemia resolved after surgical excision of the tumor. The mainstay of therapy for NICTH is treatment of the underlying malignancy. Patients with malignant PT should receive adjuvant chemotherapy and radiation therapy to reduce the risk of recurrence.

\section{Disclosure}

The authors have no financial interests or potential conflicts of interest to report in this work.

\section{References}

1. Barrio AV, Clark BD, Goldberg JI, et al. Clinicopathologic features and long term outcomes of 293 phyllodes tumors of the breast. Ann Surg Oncol. 2007;14(10):2961-2970.

2. Reinfuss M, Mituś J, Duda K, Stelmach A, Ryś J, Smolak K. The treatment and prognosis of patients with phyllodes tumor of the breast: an analysis of 170 cases. Cancer. 1996;77(55):910-916.

3. Chen WH, Cheng SP, Tzen CY, et al. Surgical treatment of phyllodes tumors of the breast: retrospective review of 172 cases. J Surg Oncol. 2005;91(3):198-194.

4. Hassouna BJ, Damak T, Gamoudi A, et al. Phyllodes tumors of the breast: a case series of 106 patients. Am J Surg. 2006;192(2):141-147.

5. Zapf J. Role of insulin-like growth factor (IFG) II and IGF binding proteins in extrapancreatic tumour hypoglycaemia. J Intern Med. 1993; 234(6):543-552.

6. Chung J, Henry RR. Mechanisms of tumor-induced hypoglycemia with intraabdominal hemangiopericytoma. $J$ Clin Endocrinol Metab. 1996;81(3):919-925.
7. Hizuka N, Fukuda I, Takano K, Okubo Y, Asakawa-Yasumoto K, Demura H. Serum insulin-like growth factor II in 44 patients with non-islet cell tumor hypoglycemia. Endocr J. 1998;45 Suppl:S61-S65.

8. Rikhof B, de Jong S, Suurmeijer AJ, Meijer C, van der Graaf WT. The insulin-like growth factor system and sarcomas. J Pathol. 2009;217(4): 469-482.

9. Renard E, Langbour-Remy C, Klein M, Le Bouc Y, Weryha G, Cuny T. Severe hypoglycemia with "Big"-IGF-2 oversecretion by a giant phyllode tumor of the breast: a rare case of non-islet cell tumorinduced hypoglycemia (NICTH). Ann Endocrinol (Paris). 2012;73(5): 488-491.

10. Hino N, Nakagawa Y, Ikushima Y, Yoshida M, Tsuyuguchi M. A case of a giant phyllodes tumor of the breast with hypoglycemia caused by high-molecular-weight insulin-like growth factor II. Breast Cancer. 2010;17(2):142-145.

11. Aguiar Bujanda D, Rivero Vera JC, Cabrera Suárez MA, et al. Hypoglycemic coma secondary to big insulin-like growth factor II secretion by a giant phyllodes tumor of the breast. Breast J. 2007;13(2):189-191.

12. Kataoka T, Haruta R, Goto T, et al. Malignant phyllodes tumor of the breast with hypoglycemia: report of a case. Jpn J Clin Oncol. 1998;28(4):276-280.

13. Grau A. Phyllodes tumors of the breast. In: Pierce LJ, editor. UpToDate. Available from: http://www.uptodate.com/home/index.html. Accessed September 24, 2014.

14. Quinlan-Davidson S, Hodgson N, Elavathil L, Shangguo T. Borderline phyllodes tumor with an incidental invasive tubular carcinoma and lobular carcinoma in situ component: a case report. J Breast Cancer. 2011;14(3):237-240.

15. Barth RJ Jr. Histologic features predict local recurrence after breast conserving therapy of phyllodes tumors. Breast Cancer Res Treat. 1999;57(3):291-295.

16. Belkacémi Y, Bousquet G, Marsiglia H, et al. Phyllodes tumor of the breast. Int J Radiat Oncol Biol Phys. 2008;70(2):492-500.

17. Chaney AW, Pollack A, McNeese MD, et al. Primary treatment of cystosarcoma phyllodes of the breast. Cancer. 2000;89(7):1502-1511.

18. Jang JH, Choi MY, Lee SK, et al. Clinicopathologic risk factors for the local recurrence of phyllodes tumors of the breast. Ann Surg Oncol. 2012;19(8):2612-2617.

19. Pezner RD, Schultheiss TE, Paz IB. Malignant phyllodes tumor of the breast: local control rates with surgery alone. Int J Radiat Oncol Biol Phys. 2008;71(3):710-713.

20. Kumar T, Patel MD, Bhargavan R, et al. Largest phyllodes tumor case report and brief review article. Indian J Surg Oncol. 2011;2(2): 141-144.

21. Morales-Vásquez F, Gonzalez-Angulo AM, Broglio K, et al. Adjuvant chemotherapy with doxorubicin and dacarbazine has no effect in recurrence-free survival of malignant phyllodes tumors of the breast. Breast J. 2007;13(6):551-556.

22. Burton GV, Hart LL, Leight GS Jr, Iglehart JD, McCarty KS Jr, Cox EB. Cystosarcoma phyllodes: effective therapy with cisplatin and etoposide chemotherapy. Cancer. 1989;63(11):2088-2092.

23. Hawkins RE, Schofield JB, Wiltshaw E, Fisher C, McKinna JA. Ifosfamide is an active drug for chemotherapy of metastatic cystosarcoma phyllodes. Cancer. 1992;69(9):2271-2275.

24. Allen R, Nixon D, York M, Coleman J. Successful chemotherapy for cystosarcoma phyllodes in a young woman. Arch Intern Med. 1985;145(6):1127-1128.

25. Tse GM, Lee CS, Kung FY, et al. Hormonal receptors expression in epithelial cells of mammary phyllodes tumors correlates with pathologic grade of the tumor: a multicenter study of 143 cases. Am J Clin Pathol. 2002;118(4):522-526.

26. Sapino A, Bosco M, Cassoni P, et al. Estrogen receptor-beta is expressed in stromal cells of fibroadenoma and phyllodes tumors of the breast. Mod Pathol. 2006;19(4):599-606. 


\section{Publish your work in this journal}

Cancer Management and Research is an international, peer-reviewed open access journal focusing on cancer research and the optimal use of preventative and integrated treatment interventions to achieve improved outcomes, enhanced survival and quality of life for the cancer patient The journal welcomes original research, clinical \& epidemiological studies, reviews \& evaluations, guidelines, expert opinion \& commentary, case reports \& extended reports. The manuscript management system is completely online and includes a very quick and fair peerreview system, which is all easy to use. Visit http://www.dovepress.com/ testimonials.php to read real quotes from published authors.

Submit your manuscript here: http://www.dovepress.com/cancer-management-and-research-journal 